\title{
Towards the development of a diffuse horizontal shortwave irradiance working standard
}

\author{
J. J. Michalsky, ${ }^{1}$ R. Dolce, ${ }^{2}$ E. G. Dutton, ${ }^{3}$ M. Haeffelin, ${ }^{4}$ W. Jeffries, ${ }^{5}$ T. Stoffel, ${ }^{6}$ J. Hickey, ${ }^{7}$
} A. Los, ${ }^{2}$ D. Mathias, ${ }^{8}$ L. J. B. McArthur, ${ }^{9}$ D. Nelson, ${ }^{3}$ R. Philipona,${ }^{10}$ I. Reda,${ }^{6}$ K. Rutledge,${ }^{11}$ G. Zerlaut, ${ }^{12}$ B. Forgan, ${ }^{13}$ P. Kiedron, ${ }^{14}$ C. Long, ${ }^{15}$ C. Gueymard ${ }^{16}$

\begin{abstract}
The first intensive observation period (IOP) to simultaneously measure diffuse horizontal shortwave irradiance (scattered solar radiation that falls on a horizontal surface) with a wide array of shaded pyranometers suggested that a consensus might be reached that would permit the establishment of a standard with a smaller uncertainty than previously achieved. A second IOP has been held to refine the first IOP measurements using a uniform calibration protocol, offset corrections for all instruments and validation of those corrections, improvements in some of the instruments, and better data acquisition. The venue for both IOPs was the Department of Energy's Atmospheric Radiation Measurement (ARM) central facility in northern Oklahoma. The nine days of measurements in October 2003 included a better mixture of clear and overcast conditions than during the first IOP and revealed considerable differences among the instruments' responses for different cloud conditions. Four of the 15 instruments were eliminated as candidates to be included in the standard because of noisy signals, inadequate offset correction, or instability with respect to the majority of the measurements. Eight pyranometers agreed to within $\pm 2 \%$ for clear-sky conditions. Three others have a high bias on clear days relative to these eight, but all eleven agree within $\pm 2 \%$ on overcast days. The differences and causes of this behavior under clear and cloudy skies are examined.
\end{abstract}

\footnotetext{
${ }^{1}$ Surface Radiation Research Branch, Air Resources Laboratory, National Oceanic and Atmospheric Administration, Boulder, Colorado, USA
} 
${ }^{2}$ Kipp \& Zonen, Inc., Bohemia, New York, USA and Delft, Netherlands

${ }^{3}$ Climate Monitoring and Diagnostics Laboratory, National Oceanic and Atmospheric Administration, Boulder, Colorado, USA

${ }^{4}$ Laboratorie de Meteorologie Dynamique, Ecole Polytechnique, Paris, France

${ }^{5}$ Yankee Environmental Systems, Inc., Turners Falls, Massachusetts, USA

${ }^{6}$ National Renewable Energy Laboratory, Golden, Colorado, USA

${ }^{7}$ The Eppley Laboratory, Inc., Newport, Rhode Island, USA

${ }^{8}$ Carter-Scott Design, Brunswick, Victoria, Australia

${ }^{9}$ Meteorological Service of Canada, Downsview, Ontario, Canada

${ }^{10}$ Physikalisch-Meterologisches Observatorium and World Radiation Center, Davos, Switzerland

${ }^{11}$ Langley Research Center, National Aeronautics and Space Administration, Hampton, Virginia, USA

${ }^{12}$ EKO Instruments Company, Ltd., Tokyo, Japan

${ }^{13}$ Bureau of Meteorology, Melbourne, Australia

${ }^{14}$ Atmospheric Sciences Research Center, State University of New York, Albany, USA

${ }^{15}$ Pacific Northwest National Laboratory, Richland, Washington, USA

${ }^{16}$ Solar Consulting Services, New Smyrna, Beach, Florida, USA

\section{Introduction}

A principal motivation for improving the measurement of diffuse horizontal shortwave irradiance (hereafter, diffuse irradiance) is the failure of radiative transfer models and improved measurements of diffuse irradiance to agree, especially for the simple case of clear, clean skies (Halthore and Schwartz 2000; Halthore et al. 2004). Zender et al. (1997), and Valero and Bush (1999) assumed a moderate aerosol absorption that produced closure in their comparisons of measurements and models of total horizontal irradiance, but did not have aerosol absorption data to justify the single scattering albedos (SSA) used as model input. Ackerman et al. (2003) used two models to compare to total horizontal irradiance measurements and found that the models agreed with measurements if a low SSA was assumed for one model and a high SSA was assumed for a second model. Further discussion with Ackerman (private communication) has resolved the model differences and suggested that modest, but unmeasured, aerosol absorption is needed to reconcile model and measurement differences as was the case for the Zender at al. (1997) and Valero and Bush (1999) papers above. Cavity radiometers measure direct beam irradiances with an uncertainty $\sim 0.35 \%$, and models and measurements of direct irradiance generally agree to within the uncertainty limits (Kato et al. 1997; Halthore et al. 1997; Halthore 
et al. 2004). Models with carefully measured inputs for clear skies generally produce higher surface diffuse irradiance than our best irradiance measurements unless the aerosol absorption is increased beyond the uncertainty limits for this input parameter. The differences are near the measurement and model uncertainties, but the bias is consistently in the same direction. The current published estimate of carefully characterized diffuse irradiance uncertainty is \pm ( $3 \%$ of reading $+1 \mathrm{~W} / \mathrm{m}^{2}$ ) (Reda et al. 2003) or $4 \mathrm{~W} / \mathrm{m}^{2}$ for a $100 \mathrm{~W} / \mathrm{m}^{2}$ diffuse irradiance sky. This diffuse irradiance measurement uncertainty is unacceptably high, and this work seeks to improve upon this uncertainty. Fundamentally, this is an important problem to resolve because it is the simplest radiative transfer problem, and the inability to come to closure on this issue leaves work on the more difficult problems of cloudy and partially cloudy skies suspect. Furthermore, a totally overcast sky only produces diffuse irradiance; therefore, high confidence in diffuse measurements is required.

This paper discusses the outcome of the second IOP conducted to simultaneously measure diffuse irradiance with mostly commercial pyranometers, but also a few prototypes. In the first IOP (Michalsky et al. 2003) eight of the fourteen instruments participating agreed to within $2 \mathrm{~W} / \mathrm{m}^{2}$ of the mean of the five most consistent instruments of the group. All except one of the remaining six pyranometers yielded a root-mean-square difference larger than $4 \mathrm{~W} / \mathrm{m}^{2}$. Some problems in this initial comparison included noisy sensors and instrument calibrations that were performed using a variety of methods resulting in a large range of uncertainty. Some instruments were offset-corrected while others were not, and the shade/receiver geometries varied among the instruments leading to differences in the amount of circumsolar light visible to the detector. 
In this experiment all of the instruments were calibrated simultaneously using the same technique. Further, all of the instruments are corrected for offsets using nighttime measurements to develop the corrections. The correction procedure is tested during the day using a capping technique that allows these predictions to be evaluated. The shade/receiver geometry effects discussed in the first IOP paper (Michalsky et al. 2003) remain, but this IOP's range in receiver sizes suggests that the differences should be small based on calculations of this effect.

In section 2 we outline the experimental details including the instruments used, the setting, and the range of conditions for which data were obtained. The offset correction procedure is described in section 3 as are the capping measurements that are used to confirm the offset correction models. The common calibration approach is presented in section 4 . Comparisons among the 15 instruments are shown in section 5, and the results are discussed in section 6. A summary of the experiment is given in the final section.

\section{Instrumentation}

Table 1 contains a list of the pyranometers used in the second IOP. Most instruments are unique in some way. For example, although we have three CM 22's the ventilation or dome material differs among the three. Likewise, the ventilation for the two CM 21 's is different. There are three Eppley PSP's. They are all standard production units and ventilated the same way, but the two from NASA Langley have thermistors mounted in the heat sink and on the inner dome to measure temperatures that are used to correct offsets. These two are the most similar in this study. The table reports two responsivities, the one sent by the owner and the one derived during the IOP using the same calibration technique for all pyranometers (see section 4). The last two columns contain data for the offsets that will be discussed in section 3 . 
The measurements were made at the ARM Southern Great Plains (SGP) central facility between Billings and Lamont, Oklahoma. Data were acquired between 8 and 16 October 2003. There was a rather uniform mixture of clear, partly cloudy, and totally overcast skies during the period. Two days were very clean and clear, with aerosol optical depths at $500 \mathrm{~nm}$ between 0.03 0.04. One of these days was used to perform calibrations on the instruments and to perform capping experiments to test the offset correction equations.

\section{Zero Offset Derivation and Correction}

The operation of the two most common types of thermopile pyranometers is explained in detail in Dutton et al. (2001) and references therein. Briefly, during the nighttime, many pyranometers should have, but generally do not have, a zero voltage output; typically, the output is less than zero, with maximum negative values on cloudless nights. The explanation for this is that single-black-detector thermopile pyranometers have cold junctions attached to the shielded body of the instrument and hot junctions attached just under the exposed absorbing detector. The dome covering the detector cools by radiating to space (at all times), which in turn cools the detector relative to the body of the instrument and, therefore, produces a negative signal. On clear nights the radiation cooling is great, yielding a large offset. For black and white pyranometers the hot and cold thermopile junctions are attached to the black and white surfaces, respectively, that are both exposed to incoming solar (and thermal) radiation. Since both junctions experience the same thermal environment there should be, and generally is, little or no thermal offset.

Numerous examples are given in Michalsky et al. (2003) for both types of pyranometers. Figure 1 illustrates the nighttime offset for two pyranometers of the single-black-detector type 
with different constructions. The instrument in Figure 1 (a) has been designed to have a reduced offset, and the instrument in Figure 1 (b) has an older design and a much larger offset. The plots in this figure contain all of the nighttime one-minute data collected over the eight days of the comparison. The $\mathrm{x}$-axis is the pyrgeometer thermopile reading and the $\mathrm{y}$-axis is the pyranometer reading with all data taken with the sun at least $7^{\circ}$ below the horizon ( $>5000$ data points). The linear, least-squares fit to the data is drawn as a dark, solid line and the linear, least-squares fit with the intercept forced to zero is the red, dashed line. The pyranometer reading forced to zero is shown because this is what one would expect when the net infrared reading from the colocated pyrgeometer is zero, that is, when the dome and receiver of the pyrgeometer are at the same temperature. For this case, the pyranometer dome and receiver should also be at the same temperature, assuming the time constant of the two processes is equivalent. Obviously the instrument in Figure 1 (a) comes closer to this expectation than the instrument in Figure 1 (b).

For all of the instruments where the nighttime data were used to predict offsets, the twoterm regression equation was used, with the exception of the instrument in Figure 1 (b), where the fit was forced through zero. This is the prescribed correction for the Eppley PSP based on Dutton et al. (2001). For the two NASA Langley Research Center PSPs in Table 1 we primarily used the correlation between the dome and case temperature measurements' difference each raised to the fourth power versus offset at night to predict the offset (see Haeffelin et al. (2001) for further details).

During the clear afternoon of 12 October 2003 we capped each of the instruments so that no light reached the detector. This was done quickly and the signal sampled at 10 -sec intervals to measure the largest negative response. This provides the daytime offset because the detector response is much more rapid than a temperature change in the dome. The temperature reaches a 
valley and eventually rises as the dome and receiver temperatures equilibrate under the cap. The capping was repeated three times, with enough time between to allow the instruments to return to their natural uncapped equilibrium. The equations derived using nighttime data were then used to predict the offset at the net infrared reading measured by the pyrgeometer during the cappings, approximately $-150 \mathrm{~W} / \mathrm{m}^{2}$.

In the next to last column of Table 1 the predicted offset using the equations based on nighttime data and a net infrared of $-150 \mathrm{~W} / \mathrm{m}^{2}$ is tabulated, and the measured offset using the lowest reading during the cappings appears in the last column. With three exceptions the offset predictions are within $1 \mathrm{~W} / \mathrm{m}^{2}$. Both the Carter-Scott Design EQ08-A and the Eppley FPP have modest offset predictions using nighttime data, but have much larger capped offsets. The EKO 802 had a dome that was larger than the others, and it could not be tested with the available caps.

\section{Common Calibration}

A favored method to calibrate pyranometers is to alternately shade and unshade the horizontal pyranometer and compare the difference to an absolute cavity radiometer that simultaneously measures the direct beam irradiance. The difference in voltages with the pyranometer shaded and unshaded is produced by the component of the direct irradiance incident on the pyranometer, which is the direct irradiance measured by a cavity radiometer multiplied by the cosine of the solar-zenith angle. Preferably, this measurement is made with the solar-zenith angle near $45^{\circ}$, and repeated as often as practical. Philipona (2002) has recently provided compelling experimental justification for this method.

Fortunately, on 12 October 2003 at the SGP site the minimum solar-zenith angle was $44.04^{\circ}$ at solar noon. The sun moved between this minimum and $45.96^{\circ}$ or within $45 \pm 0.96^{\circ}$ over 
a two-hour period providing many opportunities to repeat a two-minute shade, two-minute unshade sequence. An Eppley NIP pyrheliometer measured the direct beam on this day and then its calibration was confirmed against absolute cavity measurements on the next clear day, which occurred two days later. The change in the pyranometers' calibrations from the original calibrations assigned for the instruments by the owner can be seen in Table 1. Only five of the ten calibration factors changed by more than $1 \%$ from the original. The two largest changes were to pyranometers that had poor, rushed calibrations according to their owners.

\section{Results}

Figure 2 is an overplot of eight diffuse irradiance measurements for a very clear day (14 October 2003) after correcting for zero offsets and applying the shade/unshade calibrations. Unfortunately, one tracker carrying three instruments started late each morning and stopped before sunset. The high, stray points before 287.3 and after 287.7 in Figure 2 are due to this failure. Since the horizontal grid lines in this figure are $5 \mathrm{~W} / \mathrm{m}^{2}$ apart one can see that the spread is only $\pm 1 \mathrm{~W} / \mathrm{m}^{2}$ among these eight pyranometer readings at solar noon.

In Figure 3 two pyranometers are added to the eight in Figure 2 so that the new instruments' behavior is clearly observable. The additional instruments in Figure 3 are the Eppley FPP (fpp) and the NREL Eppley PSP (psp-nrel). The fpp appears correct near sunrise, but low throughout most of the day and just after sunset. There is more noise in this signal than present among the group of eight pyranometers. The psp-nrel is corrected using the Dutton et al. (2001) procedure, but the data are low during the day relative to the eight and also noisier than the eight stable pyranometers. 
In Figure 4 the eight instruments of Figure 2 are plotted again and the EKO Trading Co. 802 (eko) and the Carter-Scott Design EQ08-A (csd) are added. The latter instrument is $\underline{\text { reads }}$ lower than the group of eight during most of the day, and then reads higher in the late afternoon. The signal is also noisier than most instruments. The eko is only slightly lower, but noisier, than the eight stable pyranometers of Figure 2. This was the instrument that could not be capped to confirm or deny the utility of the derived nighttime offset correction equation.

The three remaining instruments in this study are plotted in Figure 5 along with the eight pyranometers of Figure 2. These three pyranometers have higher readings throughout the day, but the signals are stable in comparison to the noisy signals of the instruments discussed in Figures 3 and 4. The Yankee Environmental Systems prototype (yes) and the NREL Eppley 8-48 (848-nrel) are the highest while the CMDL Eppley 8-48 (848-cmdl) has an intermediate value when compared to the eight instruments of Figure 2 and the yes and 848-nrel. Possible explanations for these differences are discussed in section 6. Another clear day's data, not shown, duplicates the behavior in the last three figures.

In Figure 6 instruments are compared for a cloudy day. Fourteen pyranometer outputs are plotted as differences from the mean value of the group for this 3.5-hour cloudy period in which the irradiance varied between 40 and $220 \mathrm{~W} / \mathrm{m}^{2}$. The instrument responsivities used were those obtained using the shade/unshade method during the IOP. Most of the data fall within $\pm 2 \%$ of the mean. Figure 7 illustrates a continuous cloudy period two days later of 5.5 hours duration when the irradiance changed by a factor of four between 90 and $360 \mathrm{~W} / \mathrm{m}^{2}$. Again, most of the shade/unshade-calibrated pyranometer data fall within $\pm 2 \%$ of the mean. Not shown in either of these figures is the fifteenth pyranometer, the Dutton et al. (2001) corrected PSP (psp-nrel), which significantly underestimated the offset correction for both cloudy days. A small difference 
between Figures 6 and 7 is a shift of the temperature-corrected PSPs from Langley Research Center (psp-larc1 and psp-larc2) from one day to the next. The shift from the middle of the group to the lower end of the group is due to a bias in the offset correction that varies between 0 and $2 \mathrm{~W} / \mathrm{m}^{2}$; it results from dome thermistor heating and is, therefore, correlated with the magnitude of the diffuse solar irradiance.

The fairly close agreement on cloudy days for a large range of irradiances as shown in Figures 6 and 7 and the large fractional disagreement on clear days that can be inferred from Figure 5 requires explanation. The possibilities are investigated in the next section.

\section{Discussion}

Is it possible that the offset depends on the incident irradiance? Offset correction equations were derived using nighttime data. These equations were then used to estimate the offset under daytime conditions and found to agree with the capped readings to within $\pm 1 \mathrm{~W} / \mathrm{m}^{2}$ for 12 of the 14 pyranometers tested. However, there was no irradiation of the sensor in either case (at night or when capped). Could there be an offset associated with an irradiated sensor that is not captured in the dark?

This should be considered because the offset correction is based on correlations between the pyranometer offset and the net infrared measured by a pyrgeometer at night. During the day the pyranometer experiences a slightly larger net infrared radiation than the pyrgeometer measures because the absorbed radiation in the pyranometer heats the sensor by a degree or two above that of the pyrgeometer detector, which receives no solar input. This hypothesis was tested during overcast conditions (all cases when the direct beam was less that $5 \mathrm{~W} / \mathrm{m}^{2}$ and the diffuse irradiance was greater than $30 \mathrm{~W} / \mathrm{m}^{2}$ ). Figure 8 is a plot of the ratio of an instrument that shows 
no offset for any sky condition, the Eppley NREL 8-48, to an instrument that shows an increasingly negative offset with clearer conditions, the Kipp \& Zonen CM22 modified to have a sapphire outer dome, versus the cloudy-sky diffuse irradiance. For all values of diffuse irradiance, the ratio is nearly constant suggesting that the amount of radiation absorbed by the receiver does not produce an appreciable additional offset. This is typical of all of the other wellbehaved instruments in this study, but is shown only for the instruments in Figure 8.

During the first diffuse irradiance IOP the data acquisition systems were not thoroughly tested. In this experiment two tests were performed on each channel of the two Campbell Scientific CR23X $\mathrm{X}^{\mathrm{TM}}$ data acquisition systems that were used. First, the high and low inputs were connected (shorted) to each other to create a zero input voltage to determine if there was a zero bias in the logger. On channels where it could easily be performed the signal was shorted both at the logger and at the end of the cable where the instrument connection was made. No output exceeded a few tenths of a $\mathrm{W} / \mathrm{m}^{2}$. Second, a fixed standard voltage was applied to each channel obtaining results that agreed to within $0.2 \%$ of the expected output. Hence, the data acquisition system operated within expectations and cannot explain the differences that are being investigated.

How then are the differences explained among the instruments illustrated in Figures 5 and 6 or 5 and 7? Cloudy sky diffuse irradiance differs from clear sky diffuse irradiance spectrally with the clearest skies having a deep blue spectrum and cloudy skies having a spectral distribution much like the solar spectrum that is typical of full sun. Cloudy skies have a different spatial distribution of skylight. For heavy overcast, the zenith is the brightest point in the sky and the horizon is the darkest. For clear, clean skies, the brightest and darkest parts of the sky depend on the solar position. For clear, hazy skies, the horizon is bright. For partly cloudy skies, the 
spatial distribution, of course, changes unpredictably. Since the instruments have different angular responses, this could lead to relative differences in measured irradiance for these changing radiance distributions. Another effect that should be considered is the difference in the shading of detectors having different sizes. Earlier in the paper this was assumed to be a minor effect, but if there are several small differences that add in the same direction, all must be considered as possibilities.

In the first diffuse irradiance IOP paper (Michalsky et al. 2003) differences that result from different sized detectors' ability to see more or less of the circumsolar radiation, when the shading geometry is held constant, were modeled using the framework described in Major (1994). The geometry was held constant in this experiment, as well. Figure 12 of Michalsky et al. (2003) shows differences of up to about $2 \mathrm{~W} / \mathrm{m}^{2}$ for the extreme difference of $32 \mathrm{~mm}$ versus 4 $\mathrm{mm}$ diameter receivers. In this IOP the largest difference in receiver diameter is $32 \mathrm{~mm}$ versus $11 \mathrm{~mm}$, and for a clear-sky diffuse irradiance of $65 \mathrm{~W} / \mathrm{m}^{2}$, as in Figure 5, the calculated irradiance differs by about $0.7 \mathrm{~W} / \mathrm{m}^{2}$. The Eppley $8-48$ has the largest diameter detector; therefore, a larger diffuse irradiance signal is expected for this instrument. Although the magnitudes of the differences in Figure 5 are much larger than this, the tendency for the 8-48 to read higher explains a portion of the difference.

Angular responses of pyranometers differ among manufacturers and even somewhat for the same instrument models. Angular responses are usually plotted normalized with respect to the perfect Lambertian response, that is, the response of a perfect irradiance receiver should decrease as the cosine of the angle with respect to the normal to the surface of the receiver. Michalsky et al. (1995) illustrates the cosine responses of several types of detectors including some of the instruments in this study. Assuming two instruments of very different angular 
responses, a sensitivity analysis was conducted. Figure 9 represents two extremes in cosine response among the instruments in this diffuse irradiance IOP (NREL, 2003). The higher response is representative of the Eppley 8-48, and the lower response is representative of the Eppley PSP. The other pyranometers show responses that are intermediate between these two. Note that few instruments have symmetrical responses with azimuth since there is usually some measurable misalignment of optical and mechanical axes in pyranometers and the glass domes used in the instruments, although of optical quality, are not perfect. Assuming that the instruments are calibrated with the sun near $45^{\circ}$ solar-zenith angle, the cosine responses in Figure 9 can cause a maximum difference in response between cloudy and clear skies that is on the order of $0.8 \%$ at $45^{\circ}$ solar-zenith angle. The $8-48$ (with the higher response in Figure 9) reads higher in clear skies if, in cloudy conditions, it agrees with an instrument that has the lower response in Figure 9. This is because it is more responsive at the higher solar-zenith angles where clear skies tend to be brighter, but the difference is only $\sim 0.5 \mathrm{~W} / \mathrm{m}^{2}$ for the case in Figure 5. As true for the shade geometry bias the 8-48 reads higher in clear skies, but the magnitude of the difference, when combined with the geometry results, only explains about $1.2 \mathrm{~W} / \mathrm{m}^{2}$ of the differences in Figure 5.

Can the instruments' spectral sensitivities cause the difference? Since the instruments are calibrated with the shade/unshade technique they are responding to the full solar spectrum. When they measure a cloudy-sky diffuse irradiance signal they are seeing a similar spectral distribution attenuated rather uniformly across the spectrum. When the diffuse irradiance is from a clear sky, the spectrum is shifted so that almost all of the energy is in the blue and visible regions. Furthermore, the clear-sky distribution of energy depends on the aerosol loading, which redistributes energy to longer wavelengths relative to a pure Rayleigh-scattering sky. Figure 10 
illustrates this shift in the spectral distribution of diffuse irradiance for three cases, a relative clean clear sky, a very hazy clear sky, and a cloudy sky.

For all-black thermocouple instruments the response depends on the absorptivity of the receiver and the transmission of the dome or domes. For the Eppley 8-48 the response depends on the dome transmission and the difference in reflectivity of the black and white surfaces that are in contact with the hot and cold junctions of the receiver. By knowing the details of the transmissions and absorptions as a function of wavelength, the difference in responsivities to full sun and to blue sky can be calculated. Receiver absorption and dome transmission may degrade with exposure to radiation so it is possible that calculations performed using nominal values based on manufacturer's data may not describe any given instrument at any given time. Nevertheless, the available manufacturer's data can be used to evaluate the relative responsivities to scattered clear-sky irradiance and full-sun irradiance.

Model output (Gueymard 1995) for a clear, clean day (6 October 2001) during the first diffuse irradiance IOP was used to estimate the clear-sky full-sun and blue-sky responses. The signal $S$ on a single black detector pyranometer is proportional to the product of the spectral distribution of the received solar radiation $I$, the absorptivity of the receiver as a function of wavelength $A$, and the transmission of the dome or domes that cover the receiver as a function of wavelength $T$. Symbolically,

$$
S_{\text {global }} \propto \int_{\lambda} I_{\text {global }}(\lambda) A(\lambda) T(\lambda) d \lambda,
$$

where the integral is over all wavelengths. In full sun, the calibration of an instrument will be proportional to $\int_{\lambda} I_{\text {global }}(\lambda) d \lambda$ divided by $S_{\text {global }}$. In order to determine how an instrument will respond to a blue-sky spectral distribution, equation (1) is integrated using the diffuse irradiance spectral distribution substituted for the global, 


$$
S_{\text {diffuse }}(\lambda) \propto \int_{\lambda} I_{\text {diffuse }}(\lambda) A(\lambda) T(\lambda) d \lambda
$$

Multiplying the calibration constant $\int_{\lambda} I_{\text {global }}(\lambda) d \lambda / S_{\text {global }}$ by $S_{\text {diffuse }}$ yields the diffuse irradiance as measured by the pyranometer calibrated in full sun. This works since the constants of proportionality implied in Equations 1 and 2 cancel. Comparing this to $\int_{\lambda} I_{\text {diffuse }}(\lambda) d \lambda$, the fractional difference in these values, which is tabulated in column 4 of Table 2 , gives a sense of the ability of the instrument to measure the diffuse irradiance correctly if calibrated in full sun. To perform this calculation for the Eppley 8-48, simply substitute the difference in reflectivity for $\mathrm{A}$ in equations (1) and (2). Note that the difference between using the full sun or the direct beam only, as in the shade/unshade technique, has been calculated and found to have minimal difference.

The only difference that exceeds $1 \%$ of the expected diffuse irradiance is the Eppley 8 48. The white sectors of the Eppley 8-48 have a barium sulfate-based coating. A search for literature posted by vendors of barium sulfate-based coatings suggests much higher ultraviolet reflectivity than was measured by NREL and used in this calculation. Adopting higher values as suggested by the literature reduces the difference to $<0.5 \%$, which is much closer to the other values in column 4 of Table 2 . If Table 2 NREL reflectivities are adopted as realistic, then there is a dilemma that the Eppley 8-48 should read lower than most instruments by about 5\% for the spectrum used to derive the results of Table 2. Of course, the problem is that it reads high by that amount in Figure 5. Our supposition is that the white paint used in the Eppley 8-48 is more reflective in the ultraviolet than the measurements at NREL suggests because of the difficulty in measuring at ultraviolet wavelengths. If this is true spectral sensitivities cannot explain the differences. 


\section{Summary}

Fifteen pyranometers representing most current manufacturers plus a few prototypes made diffuse horizontal irradiance measurements for nine days for a variety of cloud conditions from completely overcast to completely clear skies. The instruments were calibrated simultaneously over a two-hour period using a shade/unshade technique while the sun position remained within $1^{\circ}$ of $45^{\circ}$ solar-zenith angle. Zero offset corrections were determined using nighttime data and checked using daytime cappings with 12 of 14 pyranometers yielding offsets within $1 \mathrm{~W} / \mathrm{m}^{2}$ of that predicted. One was not checked because a dark cap that fit over the dome was unavailable. An adjustment to the offset that depends on received diffuse irradiance appears to be slight.

Eight pyranometers agreed to within $\pm 2 \%$ for clear-sky conditions. Three others have a high bias on clear days relative to these eight, but all eleven agree within $\pm 2 \%$ on overcast days. Four pyranometers were eliminated from consideration as part of a standard at this juncture because we could not predict offsets during the day adequately, the instruments had noisy signals, or their biases with respect to the majority of the instruments were variable.

Three other instruments did not agree with the majority, but could not be eliminated for any of the reasons given above. Attempts to explain the remaining differences included shading geometry differences, angular response differences, and spectral response differences. Geometry and angular responses account for a fraction of the difference. Spectral response differences appear to be small if manufacturers' data for the white coating in the Eppley 8-48 is correct. In the calculations of angular and spectral response we used generic responses. In order to estimate actual differences we would need to know the details of the angular and spectral response of each 
pyranometer; information that we do not currently possess. At this point the unexplained differences in responses when clear skies prevail are not completely resolved.

Figure 11 is a summary plot of the root-mean-square (rms) errors and biases relative to the mean of the eleven stable instruments' data that has been offset-corrected and shade/unshade calibrated for daylight hours with the sun more than $6^{\circ}$ above the horizon. Figure 12 takes this one step further and perturbs the shade/unshade calibrations of these eleven instruments by forcing them to agree for the nine hours of overcast data represented in Figure 6 and 7. Using a diffuse sky to calibrate is not a typical calibration method, but this figure suggests that this technique could produce lower uncertainties if a diffuse irradiance standard existed. The data used in Figures 11 and 12 include clear, overcast, and partially overcast conditions. The mean irradiance for the 3643 one-minute samples that are compared is $106 \mathrm{Wm}^{-2}$. Comparing Figures 6 and 7 with Figure 5 suggests that the differences are smallest when skies are overcast; therefore, the positive biases and rms errors in Figures 11 and 12 for the 848-cmdl, yes, and 848nrel for clear skies must be even larger than those shown for these mixed-sky conditions.

Until the differences in Figure 5 are resolved the current study suggests that using any of the eleven instruments represented in Figure 11 would yield a typical uncertainty of $2-4 \mathrm{~W} / \mathrm{m}^{2}$ on average with higher uncertainties in clear skies and smaller uncertainties in cloudy skies.

Acknowledgments. The SGP ARM central facility staff provided much needed assistance during the IOP; we are especially indebted to Craig Webb. The authors thank the Eppley Laboratory, Inc. and Kipp \& Zonen, Inc. for supplying the absorptivity and transmission data for their instruments. The Office of Science (BER), U. S. Department of Energy, supported this research through Interagency Agreement No. DE-AI02-04ER63703. 


\section{References}

Ackerman, Thomas P., Donna M. Flynn, and Roger T. Marchand, Quantifying the magnitude of anomalous absorption, J. Geophys. Res., 108(D9), 4273, doi:10.1029/2002JD002674, 2003.

Dutton, E.G., J.J. Michalsky, T. Stoffel, B.W. Forgan, J. Hickey, D.W. Nelson, T.L. Alberta, and I. Reda, Measurement of broadband diffuse solar irradiance using current commercial instrumentation with a correction for thermal offset errors, J. Atmos. Oceanic Tech., 18, 297314, 2001.

Gueymard, C. SMARTS2, Simple Model of the Atmospheric Radiative Transfer of Sunshine: Algorithms and Performance Assessment, Rep. FSEC-PF-270-95, Fla. Sol. Energy Cent., Cocoa, 1995. Software is available from http://rredc.nrel.gov/solar/models/SMARTS/.

Halthore, R.N., S.E. Schwartz, J.J. Michalsky, G.P. Anderson, R.A. Ferrare, B.N. Holben, and H.M. Ten Brink, Comparison of model estimated and measured direct-normal solar irradiance, J. Geophys. Res., 102, 29991-30002, 1997.

Halthore, R.N. and S.E. Schwartz, Comparison of model-estimated and measured diffuse downward irradiance at the surface in cloud-free skies, J. Geophys. Res., 105, 20165-21077, 2000. 
Halthore, R. N., M. A. Miller, J. A. Ogren, P. J. Sheridan, D. W. Slater, and T. Stoffel, Further developments in closure experiments for surface diffuse irradiance under cloud-free skies at a continental site, Geophys. Res. Lett., 31, L07111, doi:10.1029/2003GL019102, 2004.

Haeffelin, M., S. Kato, A. M. Smith, C. K. Rutledge, T. P. Charlock, and J. R. Mahan, Determination of the thermal offset of the Eppley precision spectral pyranometer, Appl. Opt., 40, 472-484, 2001.

Kato, S. T.P. Ackerman, E.E. Clothiaux, J.H. Mather, G.G. Mace, M.L. Weseley, F. Murcray, and J. Michalsky, Uncertainties in modeled and measured clear-sky surface shortwave irradiances, J. Geophys. Res., 102, 25881-25898, 1997.

Major, G. V., Circumsolar correction for pyrheliometers and diffusometers, WMO/TD-No. 635, 42 pp., World Meteorological Org., Geneva, Switzerland, 1994.

Michalsky, J. J., L. C. Harrison, and W. E. Berkheiser III, Cosine response characteristics of some radiometric and photometric sensors, Solar Energy, 54, 397-402, 1995.

Michalsky, J. J., R. Dolce, E. G. Dutton, M. Haeffelin, G. Major, J. A. Schlemmer, D. W. Slater, J. R. Hickey, W. Q. Jeffries, A. Los, D. Mathias, L. J. B. McArthur, R. Philipona, I. Reda, and T. Stoffel, Results from the first ARM diffuse horizontal shortwave irradiance comparison, J. Geophys. Res., 108(D3), 4108, doi:10.1029/2002JD002825, 2003. 
National Renewable Energy Laboratory (NREL), NREL BORCAL 2003-02 Report, Golden, Colorado, USA.

Philipona, Rolf, Underestimation of solar global and diffuse radiation measured at Earth's surface, J. Geophys. Res., 107(D22), 4654, doi:10.1029/2002JD002396, 2002.

Reda, I. T. Stoffel, and D. Myers, A method to calibrate a solar pyranometer for measuring reference diffuse irradiance, Solar Energy, 74, 103-112, 2003.

Valero, F. P. J. and B. C. Bush, Measured and calculated clear-sky solar radiative fluxes during the Subsonic Aircraft Contrail and Cloud Effects Study (SUCCESS), J. Geophys. Res., 104, 27,387-27,398, 1999.

Zender, C. S., B. Bush, S. K. Pope, A. Bucholtz, W. D. Collins, J. T. Kiehl, F. P. J. Valero, and J. Vitko Jr., Atmospheric absorption during the Atmospheric Radiation Measurement (ARM) Enhanced Shortwave Experiment (ARESE), J. Geophys. Res., 102, 29,901-29,915, 1997. 
Table 1. Instruments of the IOP, Two Responsivity Measurements, and Offsets.

\begin{tabular}{|c|c|c|c|c|c|}
\hline Instrument & $\begin{array}{l}\text { Serial } \\
\text { No. }\end{array}$ & $\begin{array}{l}\text { Response (old) } \\
\left(\mu \text { volts } / \mathrm{Wm}^{-2}\right)\end{array}$ & $\begin{array}{l}\text { Response (new) } \\
\left(\mu \text { volts } / \mathrm{Wm}^{-2}\right)\end{array}$ & $\begin{array}{l}\text { Predicted } \\
\text { offset }\left(\mathrm{Wm}^{-2}\right)\end{array}$ & $\begin{array}{l}\text { Capped } \\
\text { offset }\left(\mathrm{Wm}^{-2}\right)\end{array}$ \\
\hline cm22-wrc ${ }^{a}$ & 990010 & 11.52 & $11.46 \mu \mathrm{v} / \mathrm{Wm}^{-2}$ & -1 to 0 & -1 to 0 \\
\hline $\mathrm{cm} 22 \bmod -\mathrm{kz}^{\mathrm{b}}$ & SoDP & 8.72 & 8.66 & -1 to 0 & -1 to 0 \\
\hline $\mathrm{cm} 22-\mathrm{kz}^{\mathrm{c}}$ & 010044 & 9.52 & 9.54 & -2 to -1 & -2 to 0 \\
\hline $\mathrm{cm} 11-\mathrm{kz}^{\mathrm{d}}$ & 027787 & 5.04 & 5.098 & -3 & -3 \\
\hline $\mathrm{cm} 21-\mathrm{kz}^{\mathrm{e}}$ & 021041 & 11.32 & 11.33 & -3 & -3 \\
\hline $\mathrm{cm} 21-\mathrm{msc}^{\mathrm{f}}$ & 980470 & 18.06 & 18.03 & -5 to -6 & -5 to -6 \\
\hline $\mathrm{fpp}^{\mathrm{g}}$ & fpp & 4.43 & 4.42 & -2 & -10 to -9 \\
\hline $848-\mathrm{cmdl}^{\mathrm{h}}$ & 32347 & 8.81 & 8.75 & -1 to 0 & 0 \\
\hline 848-nrel ${ }^{\mathrm{i}}$ & 32858 & 9.084 & 9.052 & 0 & 0 \\
\hline psp-nrel ${ }^{j}$ & 31256 & 7.561 & 7.712 & -12 to -11 & -12 to -11 \\
\hline psp-larc $2^{\mathrm{k}}$ & 30849 & 7.841 & 7.733 & -9 & -8 \\
\hline yes $^{1}$ & 102 & 5000 & 4863 & 1 & 1 \\
\hline $\mathrm{eko}^{\mathrm{m}}$ & $\mathrm{f} 03007 \mathrm{f}$ & 7.06 & 6.986 & -1 & No capping \\
\hline $\operatorname{csd}^{\mathrm{n}}$ & 8401 & 967 & 1023 & 0 & -5 to -2 \\
\hline psp-larc $1^{\mathrm{k}}$ & 31562 & 9.117 & 9.061 & -10 & -10 \\
\hline
\end{tabular}

${ }^{\mathrm{a}}$ Kipp \& Zonen, Inc. CM 22; World Radiation Center ventilation with heated air flow.

${ }^{\mathrm{b}}$ Kipp \& Zonen, Inc. CM 22; Kipp \& Zonen CV2 ventilator; sapphire outer dome.

${ }^{\mathrm{c}} \mathrm{Kipp} \&$ Zonen, Inc. CM 22; Kipp \& Zonen CV2 ventilator.

${ }^{\mathrm{d}}$ Kipp \& Zonen, Inc. CM 11; Kipp \& Zonen CV2 ventilator.

${ }^{\mathrm{e}}$ Kipp \& Zonen, Inc. CM 21; Kipp \& Zonen CV2 ventilator.

${ }^{f}$ Kipp \& Zonen, Inc. CM 21; Meteorological Services of Canada-designed ventilator.

${ }^{\mathrm{g}}$ Eppley un-ventilated prototype.

${ }^{\mathrm{h}}$ Eppley ventilated 8-48 from NOAA/Climate Monitoring and Diagnostics Laboratory.

${ }^{\mathrm{i}}$ Eppley un-ventilated 8-48 from DOE/National Renewable Energy Laboratory.

${ }^{\mathrm{j}}$ Eppley ventilated PSP from DOE/National Renewable Energy Laboratory.

${ }^{\mathrm{k}}$ Eppley ventilated PSP from NASA/Langley Research Center; measured case/inner dome temperatures.

${ }^{1}$ Yankee Environmental Systems, Inc. prototype; YES ventilator.

${ }^{\mathrm{m}}$ EKO Instruments Co., Ltd. 802 EKO ventilator.

${ }^{\mathrm{n}}$ Carter-Scott Design EQ08-A; not ventilated. 
Table 2. Difference in clear-sky diffuse irradiance responses when calibrated in full sun. $\begin{array}{llll}\text { Pyranometer } & \text { Dome glass (T) } & \text { Sensor absorber (A) } \quad \Delta \mathrm{I}_{\text {diffuse }} / \mathrm{I}_{\text {diffuse }}\end{array}$

\begin{tabular}{llll}
\hline Eppley PSP & WG295 & Parson's black & $0.1 \%$ low \\
Eppley 8-48 & WG295 & NREL-measured & $5.5 \%$ low \\
Eppley 8-48 & WB295 & white reflectivity \\
& & Standard BaSO 4 white & $0.5 \%$ low \\
Kipp\&Zonen CM11 & K5 & reflectivity & \\
Kipp\&Zonen CM21 & K5 & Kipp data & $0.5 \%$ low \\
Kipp\&Zonen CM22 & Quartz & Kipp data & $0.5 \%$ low \\
\hline
\end{tabular}



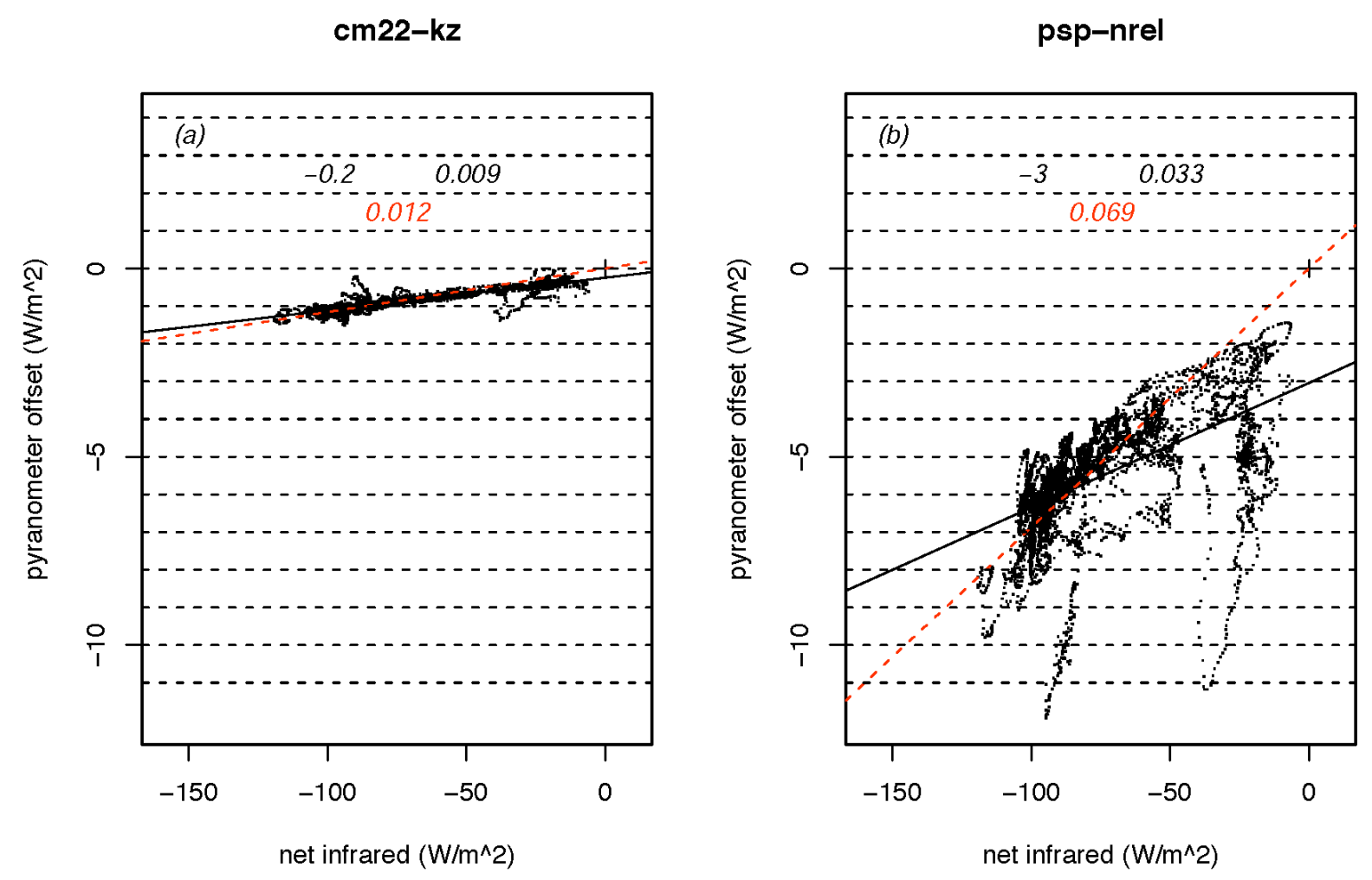

Figure 1. Nighttime data ( $>5000$ points) during the IOP with pyranometer offset plotted versus net infrared irradiance from a co-located pyrgeometer for two pyranometers. The dark line is a linear least-squares fit to the data (offset and slope are black numbers) and the red, dashed line is a linear fit with a forced zero intercept (slope in red). The large spread of points in the figure on the right is typical of all instruments of this model, and there are no obvious reasons to exclude them from the analysis. 


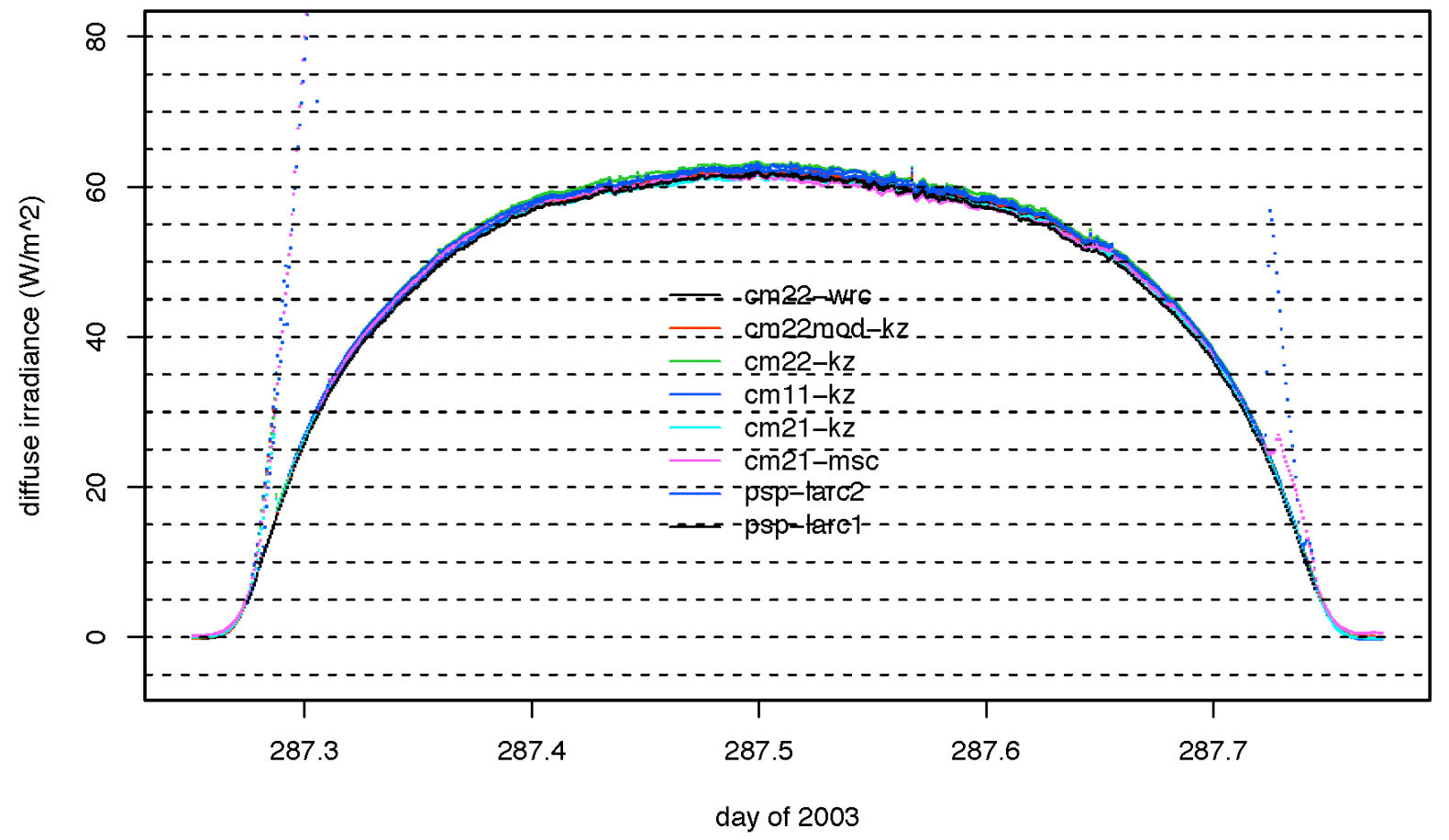

Figure 2. Overplot of eight instruments named on plot after correction for offset and with a common shade/unshade calibration applied. One tracker that carried three instruments started tracking late and ended tracking early exposing pyranometers to direct sunlight, and these points are removed from consideration in our analysis. 


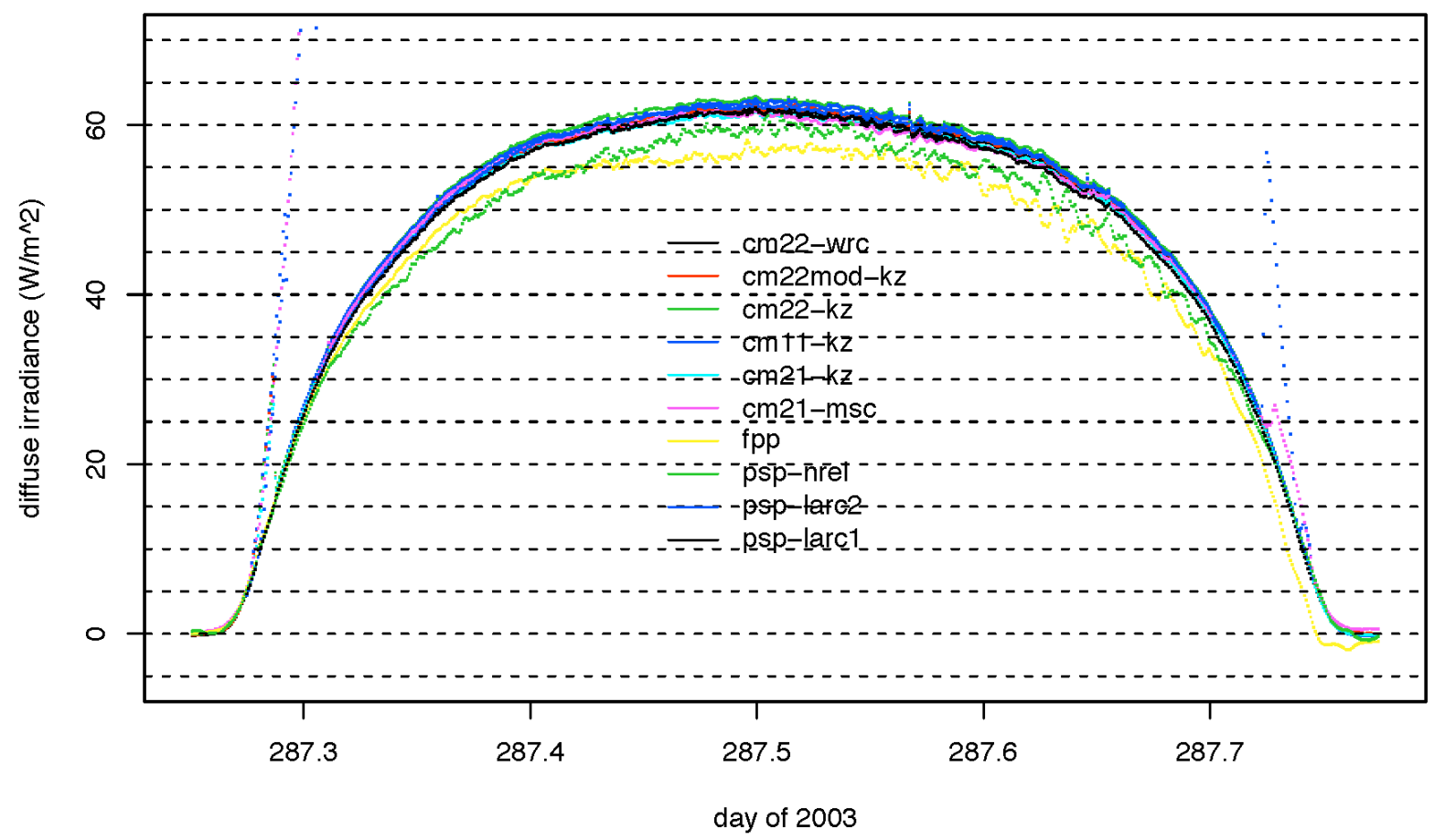

Figure 3. Same instruments as in Figure 2 plus the Eppley prototype (fpp) and the NREL Eppley PSP (psp-nrel); the latter is corrected for zero offset using the Dutton et al. (2001) method. The two instruments are lower than the eight throughout most of the day, and the fpp is too low just after sunset. Both are noisier than the group of eight from Figure 2. 


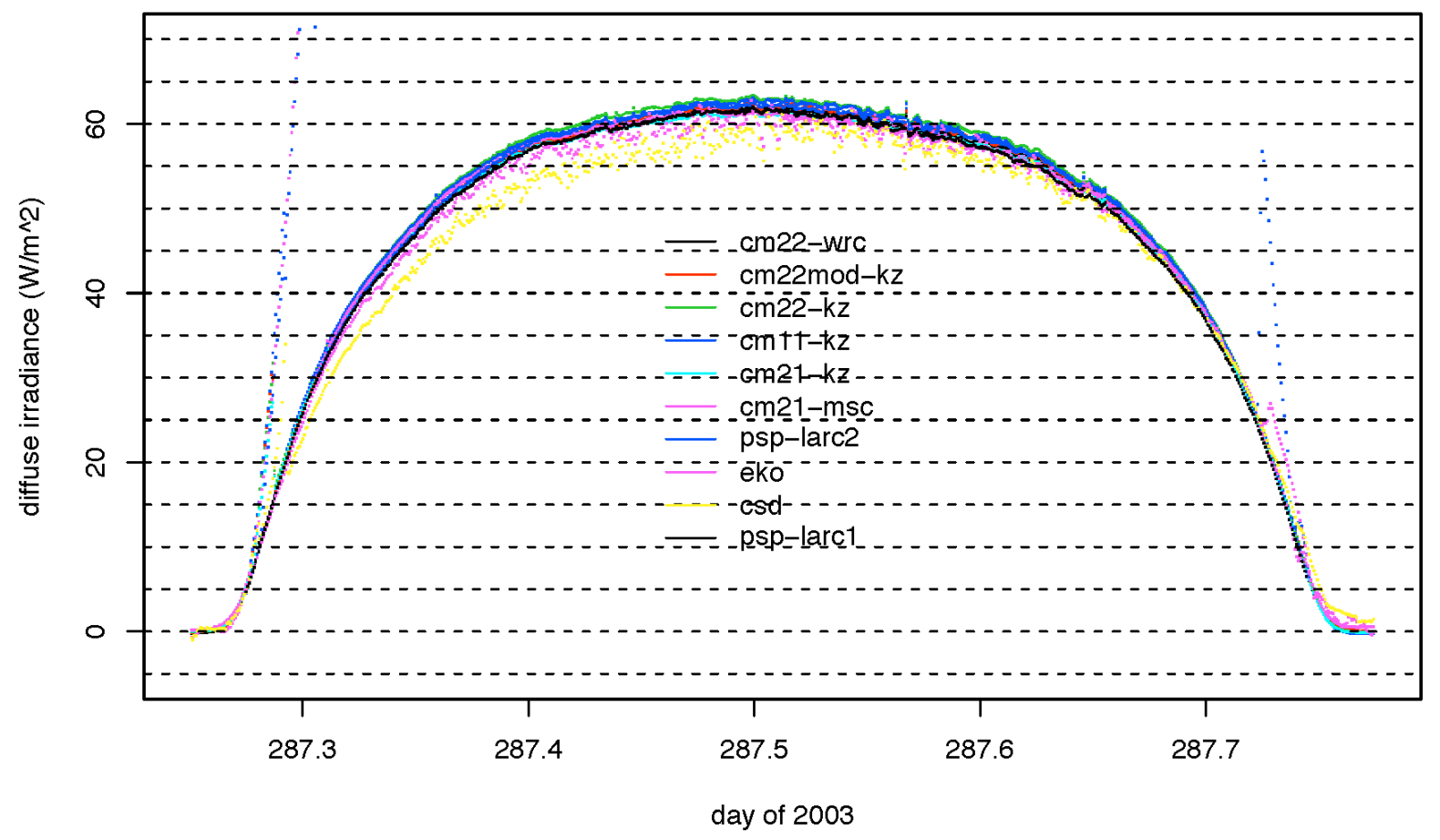

Figure 4. Same instruments as in Figure 2 plus the Carter-Scott EQ08-A (csd) and the EKO Instruments 802 (eko). The csd reads too low during most of the day relative to the eight until late afternoon when it is higher. The eko is just slightly lower that the eight pyranometers of Figure 2. Both the csd and the eko are noisier than the eight instruments. The eko was the instrument that was not capped because of the large dome. The validity of the offset equation could not, therefore, be tested. 


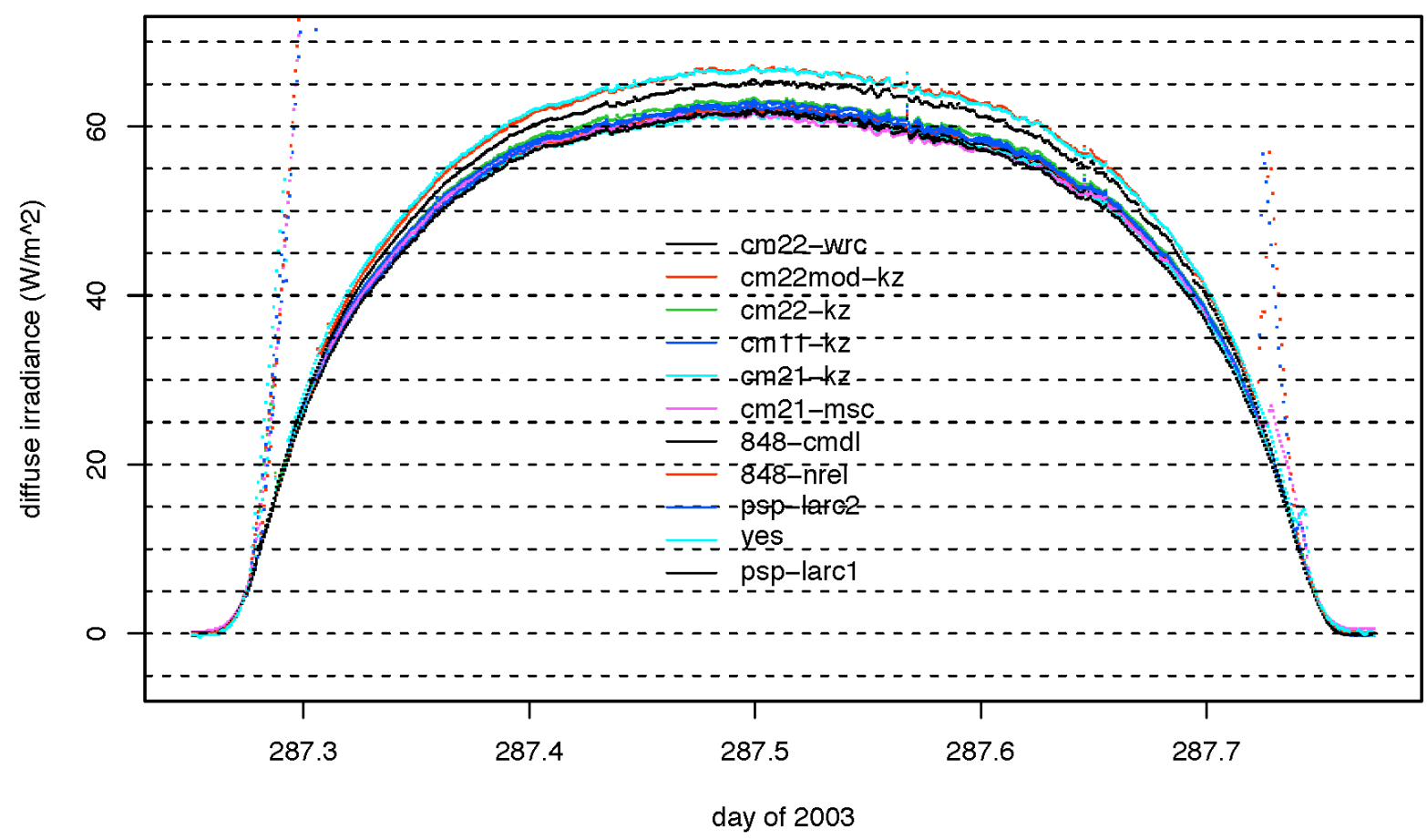

Figure 5. The eight pyranometers of Figure 2 plus two Eppley 8-48s (848-nrel and 848-cmdl) and the Yankee prototype (yes). These last three read high relative to the eight. They do not have noisy signals like the instruments of the last two figures. Attempts to explain the differences are given in the text. 


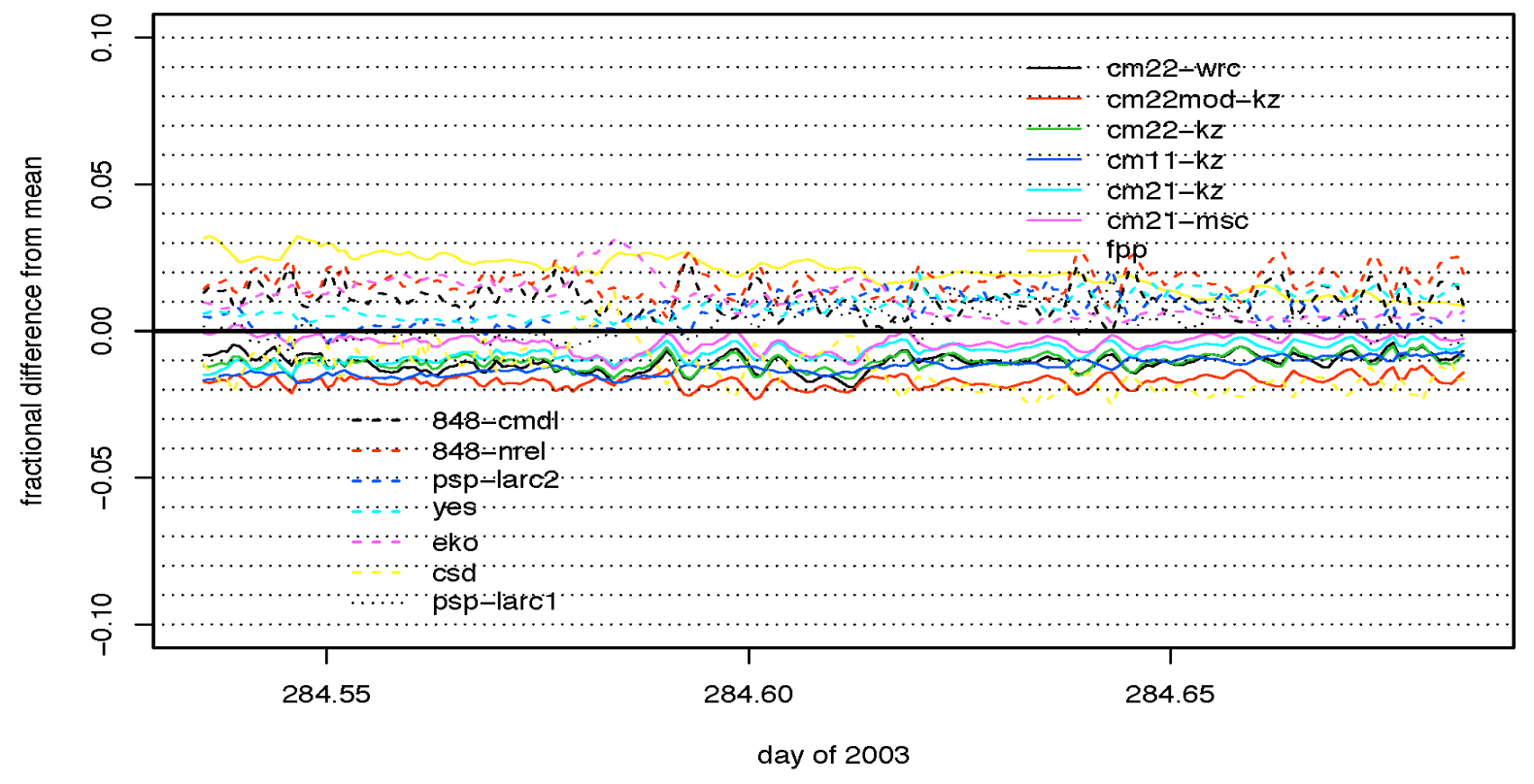

Figure 6. Fourteen instruments are compared to their mean for this 3.5 -hour cloudy period while the diffuse irradiance varies between 40 and $220 \mathrm{~W} / \mathrm{m}^{2}$. The pyranometers use the shade/unshade calibration for these data. The variation is almost entirely within $\pm 2 \%$ of the mean. 


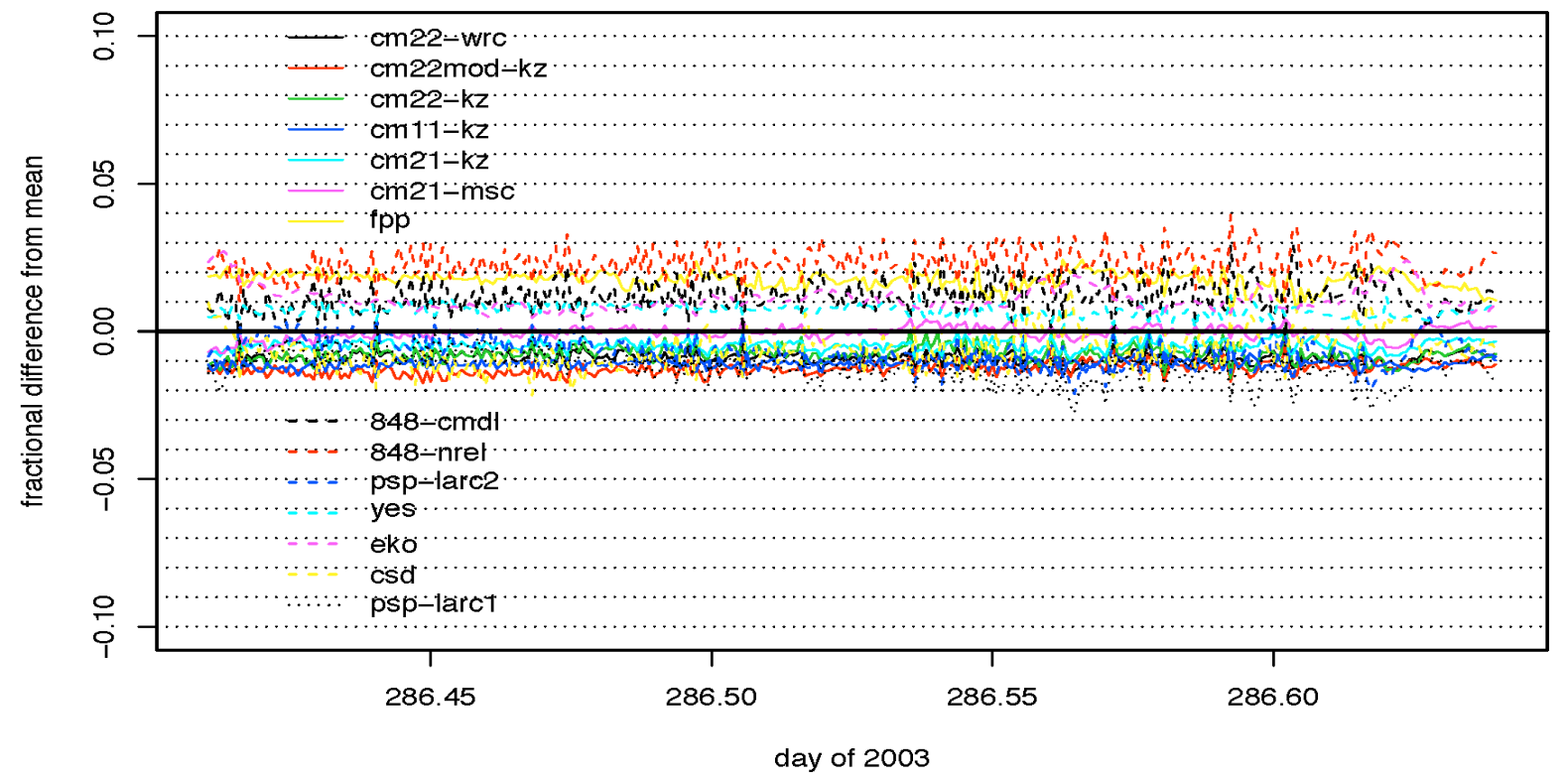

Figure 7. Fourteen instruments are compared to their mean for this 5.5-hour cloudy period where the diffuse irradiance varies between 90 and $360 \mathrm{~W} / \mathrm{m}^{2}$. The pyranometers use the shade/unshade calibration for these data. The variation is almost entirely within $\pm 2 \%$ of the mean. 


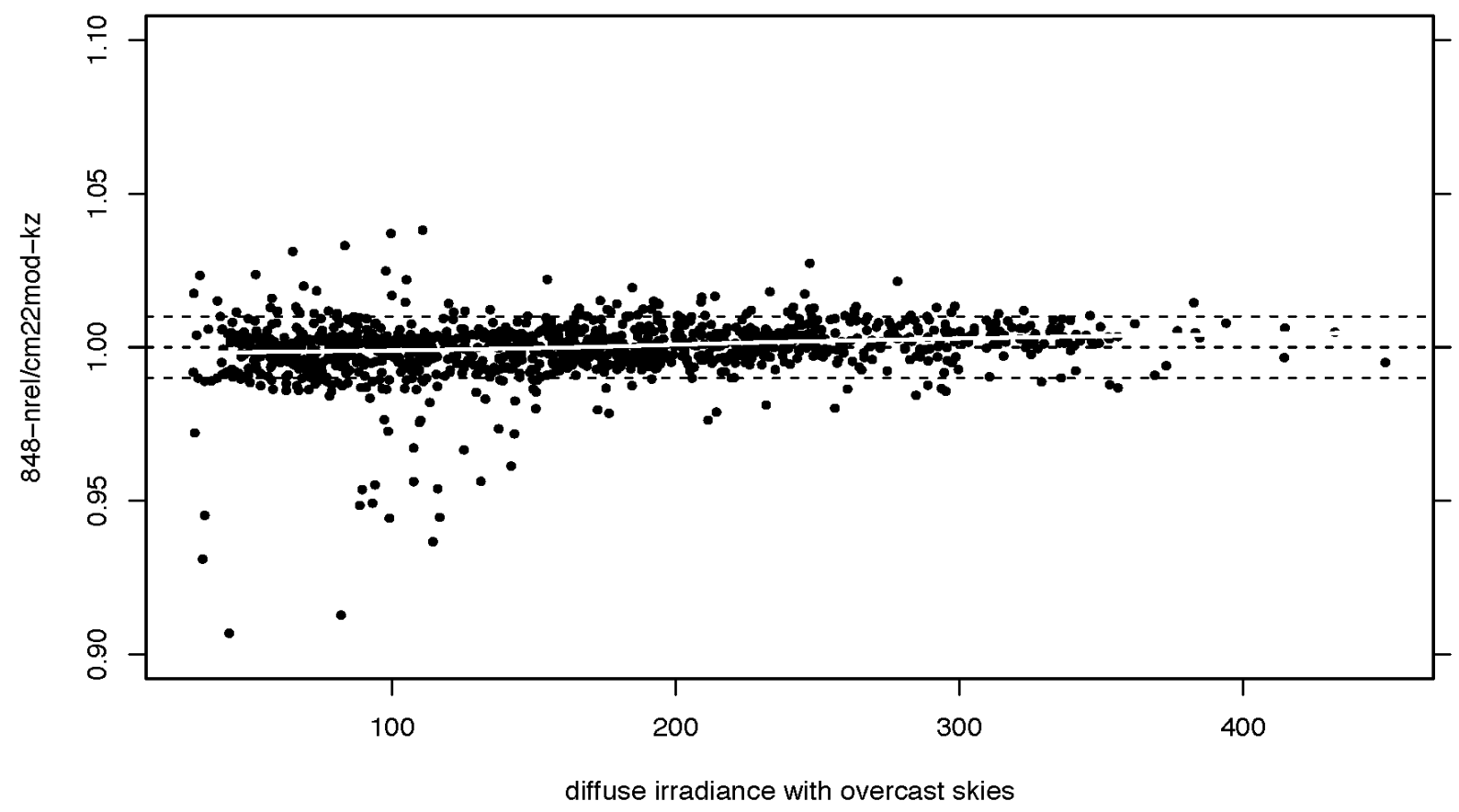

Figure 8. The near constancy of this ratio of diffuse irradiances for cloudy skies suggests that there is a negligible increased offset caused by the pyranometer detector's absorption of solar radiation, and slight rise in temperature, which a pyrgeometer does not experience during the day. 


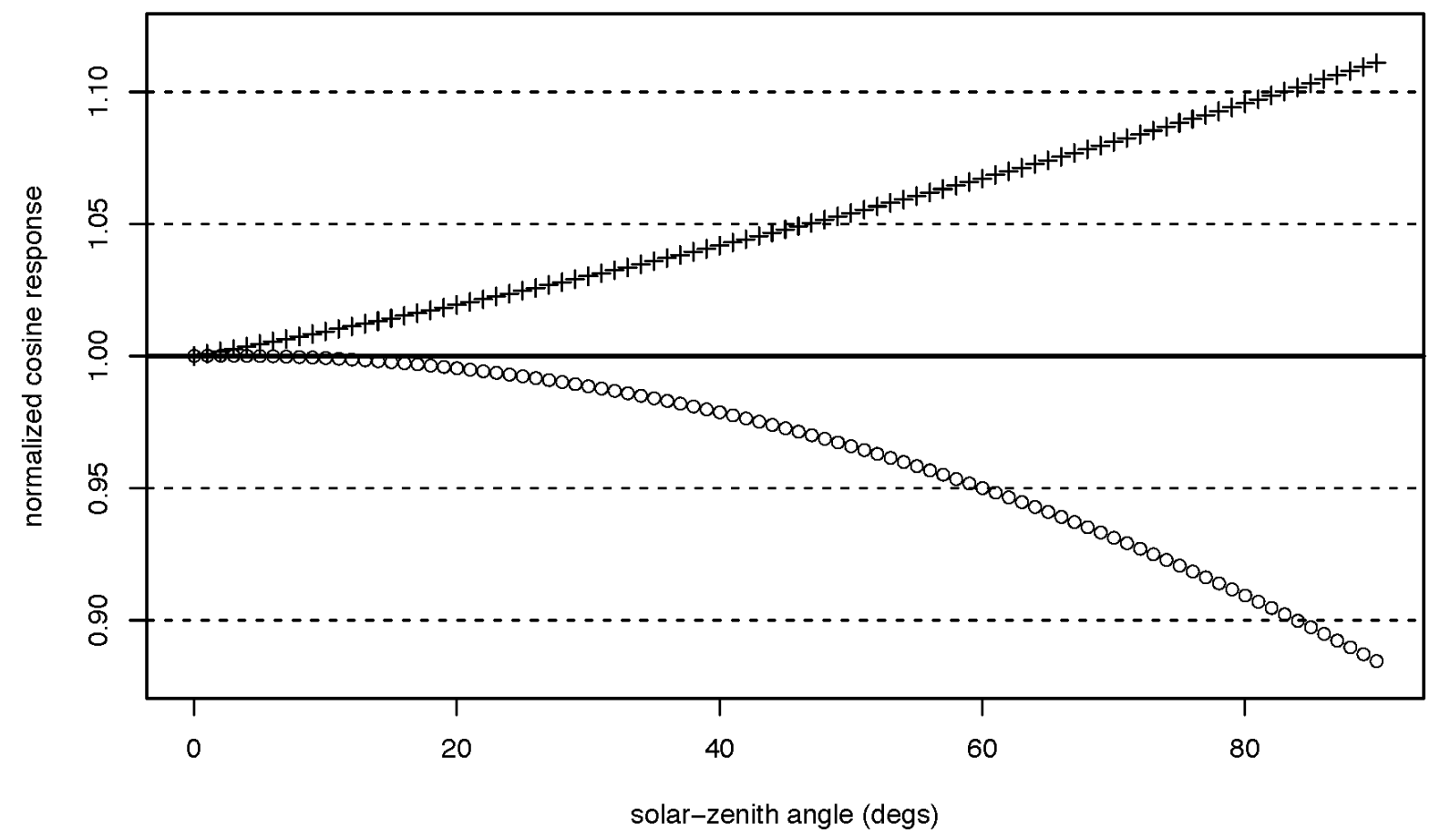

Figure 9. Normalized cosine responses of two instruments in this IOP. These represent the instruments with the highest and lowest responses at large zenith angles. 


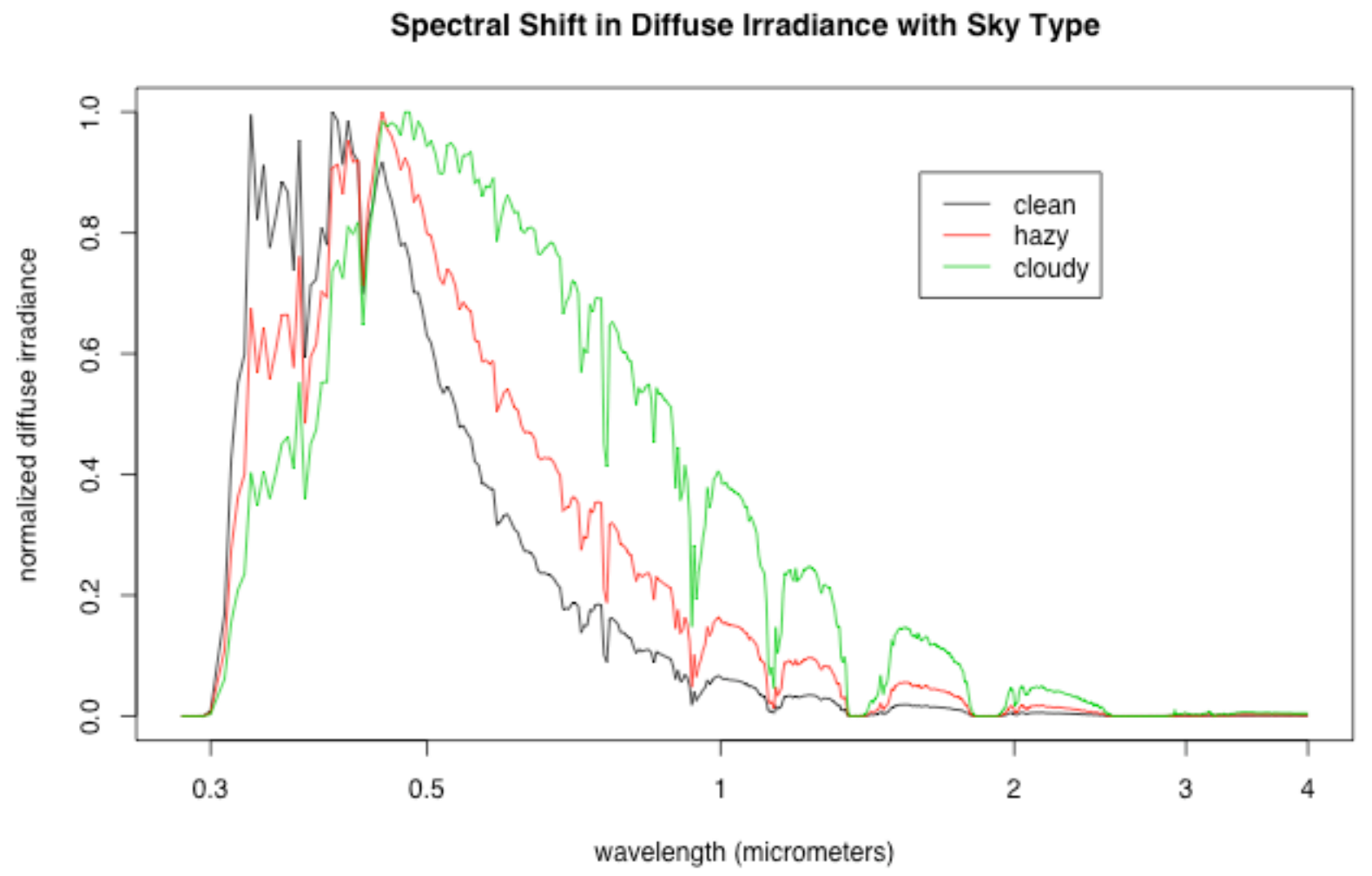

Figure 10. The normalized diffuse spectral irradiance for three sky conditions. 


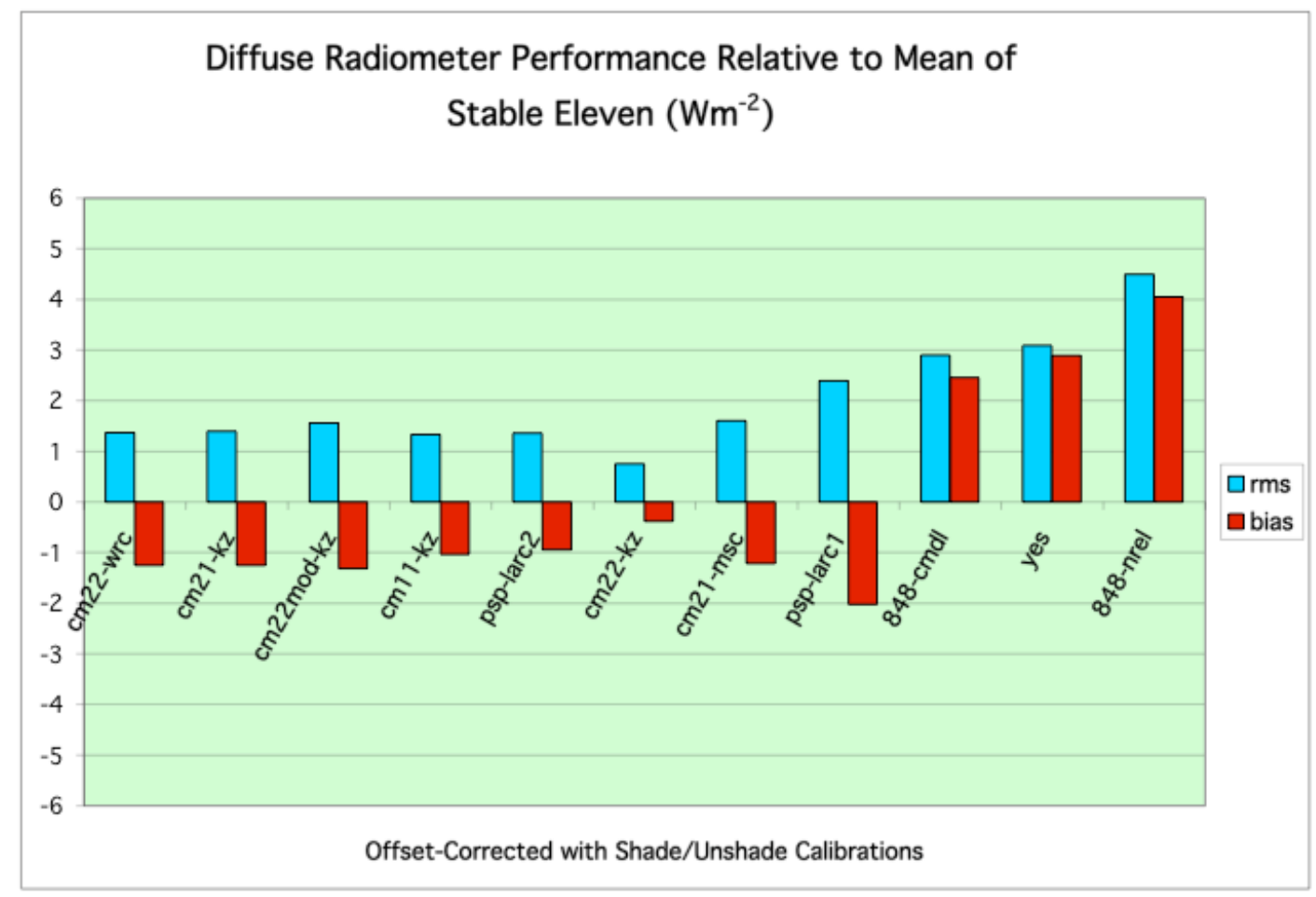

Figure 11. Summary plot of root-mean-square errors and biases from the mean of the eleven stable pyranometers using offset-corrected and shade/unshade calibrated data. 


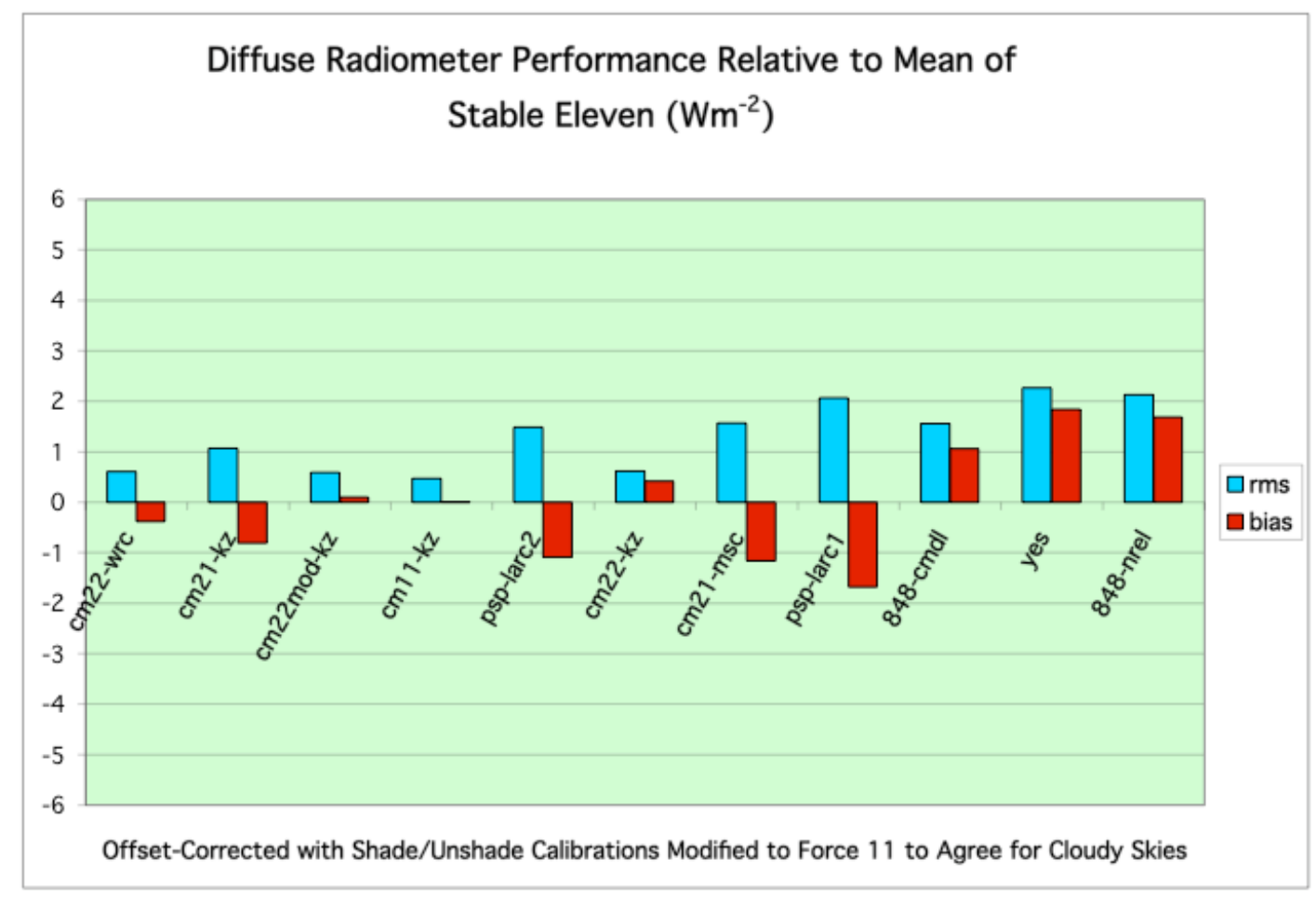

Figure 12. Summary plot of root-mean-square errors and biases from the mean of the eleven stable pyranometers using offset-corrected and shade/unshade calibrations that have been slightly modified to force agreement of the eleven pyranometers under totally overcast conditions. 